\title{
FAT INFILTRATION IN THE TISSUES OF THE NEWBORN INFANT
}

\author{
BY \\ W. AHERNE \\ From the Department of Pathology, Radcliffe Infirmary, Oxford
}

(RECEIVED FOR PUBLICATION JANUARY 6, 1965)

Although there are many studies on the significance of fat droplets in parenchymal cells, few of them relate to the neonatal period. Scott (1961) found fat infiltration of the myocardium in infants who had been in respiratory distress. She associated this with other necropsy findings which suggested heart failure. Gruenwald (1949) observed fat vacuolation of the liver, more marked in the right lobe, together with other changes more clearly degenerative, in infants who had suffered prenatal hypoxia. Emery and Finch (1954), who were also interested in differences between the liver lobes, estimated chemically the fat content of the foetal and the neonatal liver, having first excluded as abnormal any specimen showing stainable fat droplets. They found a considerable variation in fat content, and a tendency for the right lobe to contain more after 24 hours of age. Inspection of their figures further suggests an increase in total mean fat content (based on dry weight) from $9 \%$ in the first 5 hours to $16 \%$ in the second day.

These authors have interpreted fat droplet infiltration as pathological. Dorkin and Weinberg (1949) observed more stainable fat in the neonatal human liver than they could attribute to any pathological cause, and concluded that its presence was a normal part of neonatal metabolism. If species differences do not invalidate comparisons, this view accords with experimental findings in newborn animals. Hard, Reynolds, and Winbury (1944) found a marked rise in the fat content of the guineapig liver during the last quarter of gestation. At term the level had reached $33-35 \%$ (dry weight). Immediately after birth this began to fall, like the liver glycogen level but less steeply, until the adult level of about $12 \%$ was attained in 3 to 4 days. Fat staining of the normal newborn rabbit liver (writer's observations) suggests a similar pattern of change.

It is now well known that tissue glycogen levels are high at term and are rapidly mobilized in the early neonatal period (Shelley, 1964). The possibility of changes in tissue fat content determined by birth prompted the following study.

\section{Material and Methods}

The series comprised 69 infants, studied consecutively, of whom 7 were stillborn. Of the 62 liveborn infants about two-thirds were premature; all died in the first week of life. Causes of death need not be specified in detail; the necropsy findings were a representative cross-section of neonatal pathology. Nine of the infants came also into a trial of immediate feeding (Smallpeice and Davies, 1964); a few of these had been fed with expressed breast milk as early as 1-2 hours after delivery.

At necropsy, samples were taken of liver, myocardium, lung, kidney, diaphragm, rectus abdominis, and tibialis anterior. These tissues were mostly sectioned fresh on a Slee cryostat at $5 \mu$ and stained with Oil Red O. In a small proportion of cases stored formalin-fixed tissues were used, similarly cut and stained. Detailed histochemical analyses were made in a few representative cases, using Nile Blue Sulphate, periodic acid-Schiff, and Sudan Black B after acetone extraction. During the study 20 sets of samples were taken from older children for comparison.

In assessing the results the method of rank correlation was used. To test, for example, the correlation of tissue fat content with postnatal age, the procedure, in outline, was as follows. First, all the cases were ranked, with respect to each tissue separately, in descending order of fat droplet content as determined microscopically by visual assessment. A number was assigned to each case denoting its rank in each particular tissue series. Next, the cases were again ranked, now with respect to postnatal age in hours, in descending order of magnitude; again a number was assigned to each case denoting its rank. Finally, the tissue fat rank number was compared with the age rank number. Theoretically, perfect correlation would have been indicated by the coincidence of ranks; 1 with 1,2 with 2 , and so on. In practice the degree of correlation was obtained by means of Spearman's coefficient, and from this an estimate of the more widely used correlation coefficient, $r$, as described by Tippett (1952). 
The ranked sequences also enabled comparisons to be made between one tissue and another, between premature and mature infants, and (in a more limited way) between one disease and another.

Chemical estimations of tissue carbohydrate levels were available in most cases, since a study of carbohydrate metabolism was made concurrently (Shelley, 1964).

\section{Results}

Liver and Muscle. Sequential changes related to postnatal age were soon observed in samples of liver, myocardium, respiratory muscle (diaphragm, rectus abdominis), and skeletal muscle. Particular attention was therefore given to these tissues.

STILLBORN INFANTS. In the small group of stillborn infants examined, liver, myocardium, respiratory, and skeletal muscles were all devoid of fat droplets.

LIVEBORN INFANTS. In liveborn infants, especially in those of more than 30 weeks' gestation, fat droplet infiltration increased steadily with advancing postnatal age in liver, myocardium, respiratory, and skeletal muscles. This phenomenon appeared unrelated to the type of illness from which the infant had suffered. Infiltration reached maximum intensity at about 48 hours when, by and large, it was much greater than any seen in older children. After 48 hours the direct relation with postnatal age began to disappear: at 72 hours the intensity of fat infiltration was no greater than that at $\mathbf{4 8}$ hours, and it was often less. Too few cases were available to pursue the study beyond 72 hours.

TABLE 1

COEFFICIENTS OF CORRELATION BETWEEN TISSUE FAT DROPLET DENSITY AND POSTNATAL AGE TO 48 HOURS (Gestation: 30 Weeks - Term)

\begin{tabular}{|c|c|c|c|}
\hline Tissue & & Coefficient, $r$ & Significance \\
\hline $\begin{array}{l}\text { Liver } . . \\
\text { Myocardium } \\
\text { Diaphragm } \\
\text { Rectus abdom. } \\
\text { Tibialis ant. }\end{array}$ & $\begin{array}{ll}\ldots & \\
\cdots & \cdots \\
\cdots & \cdots \\
\cdots & \cdots\end{array}$ & $\begin{array}{l}0.65 \\
0.47 \\
0.66 \\
0.75 \\
0.52\end{array}$ & $\begin{aligned} \mathbf{p} & <0.01 \\
\mathbf{p} & <0.01 \\
\mathbf{p} & <0.01 \\
\mathbf{p} & <0.01 \\
\mathbf{0} .05<\mathrm{p} & <\mathbf{0 . 0 2}\end{aligned}$ \\
\hline
\end{tabular}

The correlation between fat content and age is shown numerically in Table 1 . Typical histological appearances are shown in Figs. 1 to 3.

Fat droplets tended to appear earliest, and to be largest, in the liver. Infiltration began usually in the periportal cells. In muscle other than cardiac the droplets lay in parallel rows, mainly longitudinally, in relation to myofibrils. The intensity of infiltration was consistently greater in respiratory than in skeletal muscle; in 26 comparisons of diaphragm
TABLE 2

COEFFICIENTS OF CORRELATION BETWEEN FAT DROPLET DENSITY IN PAIRS OF TISSUES FROM THE SAME BODY

\begin{tabular}{|c|c|c|c|c|}
\hline & Liver & Myocardium & Diaphragm & Rectus Ab. \\
\hline $\begin{array}{ll}\text { Liver . } & \ldots \\
\text { Myocardium } & \ldots \\
\text { Diaphragm } & . \\
\text { Rectus abdom. } \\
\text { Tibialis ant. }\end{array}$ & $\begin{array}{l}0.62 \\
0.74 \\
0.68 \\
0.81\end{array}$ & $\begin{array}{l}0.69 \\
0.69 \\
0.69\end{array}$ & $\begin{array}{l}0.85 \\
0.77\end{array}$ & 0.85 \\
\hline
\end{tabular}

In each instance $p<0.01$.

with tibialis anterior from the same case the diaphragm contained more fat in 22 instances. In general, however, the rate of fat infiltration, as judged by the rank achieved in the separate tissue series, was much the same in liver, myocardium, and muscle in any particular case. This is shown in Table 2, where pairs of ranked tissues are correlated.

The intensity of fat infiltration at any particular postnatal age depended significantly on maturity, being clearly greater in the more mature infants.

The series contained too few dysmature infants for rigorous appraisal; however, one of the most strikingly infiltrated sets of tissues came from a dysmature infant who died at only 10 hours of age.

The relation of tissue fat content (estimated visually) and carbohydrate content (estimated chemically; Shelley, 1964) was inverse. It was not particularly close, however, and only appeared when the cases were broadly classified into four groups $(3+, 2+, 1+, 0)$ according to fat content. A limited analysis of this topic is shown in Table 3.

Other Tissues. Samples of kidney showed some degree of fat droplet infiltration with advancing postnatal age, affecting mainly the proximal convoluted tubules. This was much less clear cut than in the tissues discussed above and was not actively studied. The lung was unique among the tissues sampled: here alone fat droplets (which appeared in the bronchiolar mucosa) were present in greater numbers in immature than in mature infants and did not

TABLE 3

RELATION OF FAT DROPLET CONTENT TO TOTAL CARBOHYDRATE CONTENT (POOLED CASES)

\begin{tabular}{|c|c|c|c|}
\hline \multirow[t]{2}{*}{ Fat Content } & \multicolumn{3}{|c|}{$\begin{array}{l}\text { Total Carbohydrate Content } \\
\text { (mg./g. wet weight) }\end{array}$} \\
\hline & Liver & Myocardium & Diaphragm \\
\hline $\begin{array}{c}++ \\
++ \\
+ \\
0\end{array}$ & $\begin{array}{r}2 \cdot 2 \\
7 \cdot 5 \\
9 \cdot 8 \\
10 \cdot 8\end{array}$ & $\begin{array}{r}9 \cdot 9 \\
9 \cdot 7 \\
23 \cdot 5 \\
21 \cdot 6\end{array}$ & $\begin{array}{l}1 \cdot 3 \\
6 \cdot 0 \\
4 \cdot 5 \\
3 \cdot 5\end{array}$ \\
\hline
\end{tabular}




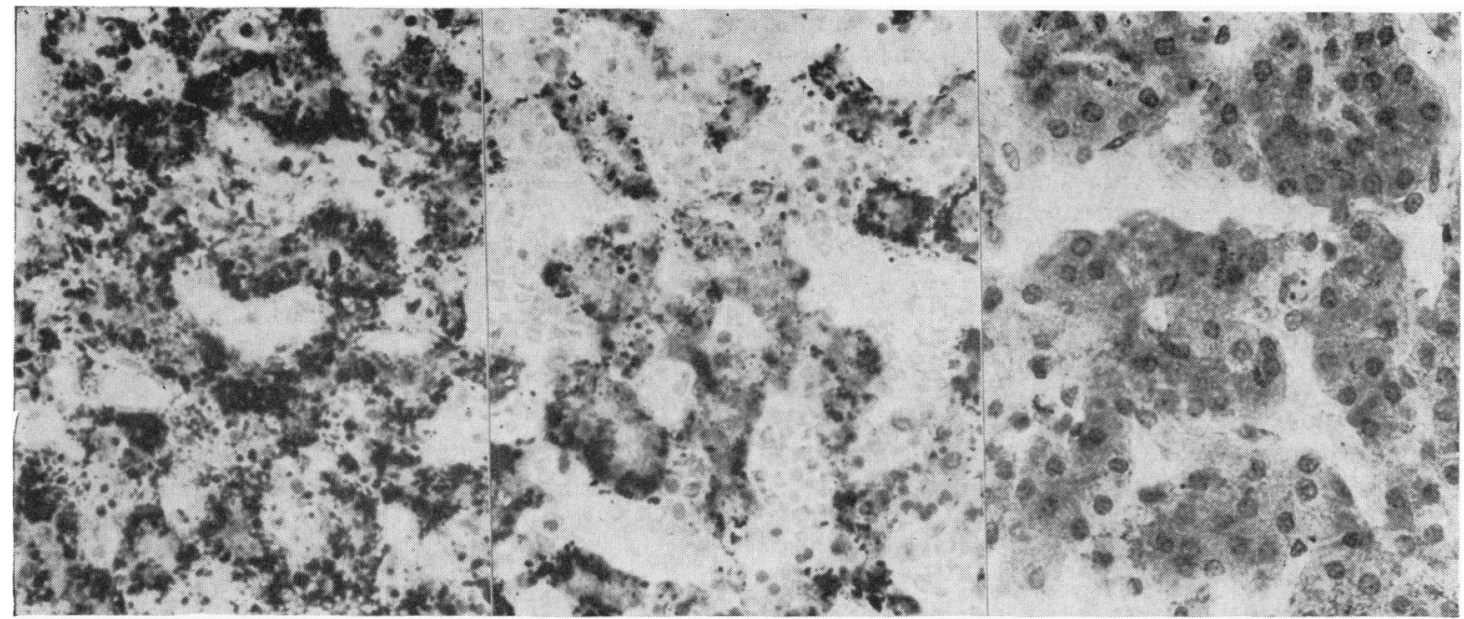

(a)

(b)

(c)

Fig. 1.-Liver parenchyma, showing (a) marked, (b) moderate, and (c) no fat infiltration. (Frozen section, Oil Red 0 , Blue filter. $\quad \times 243$.)

change with age. Moreover, it was present here alone in stillbirths. These observations were not pursued further.

Histochemical Analysis. Differential staining showed that, in all cases examined, the droplets consisted of neutral fat.

\section{Discussion}

In most cells fat is present in the form of a micellar dispersion (Dixon, 1958) and so cannot be demonstrated by fat soluble dyes. It is maintained in this form by phospholipid. Broadly, the conditions that determine its aggregation into droplets are these: deficiency of phospholipid, a block in utilization due to some lesion in the cell, or the delivery of fat in unusually large amounts to the normal cell.

The familiar fat infiltration of adult tissues can reasonably be explained in terms of phospholipid deficiency, as in malnutrition, or of katabolic block, as in prolonged anaemia, severe sepsis, or chemical intoxication. Not unnaturally, therefore, the pres-

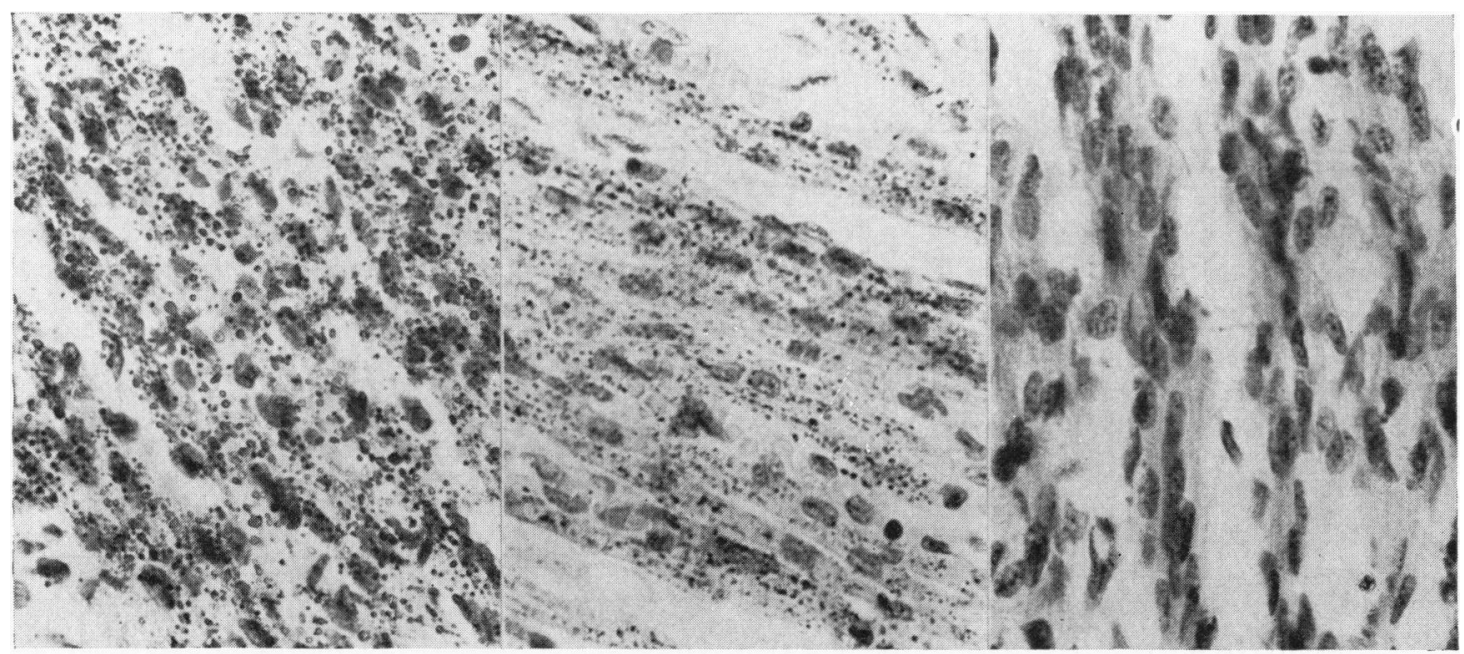

(a)

(b)

(c)

FIG. 2.-Myocardium, showing (a) marked, (b) moderate, and (c) no fat infiltration. (Frozen section, Oil Red $0 . \quad \times 300$.) 


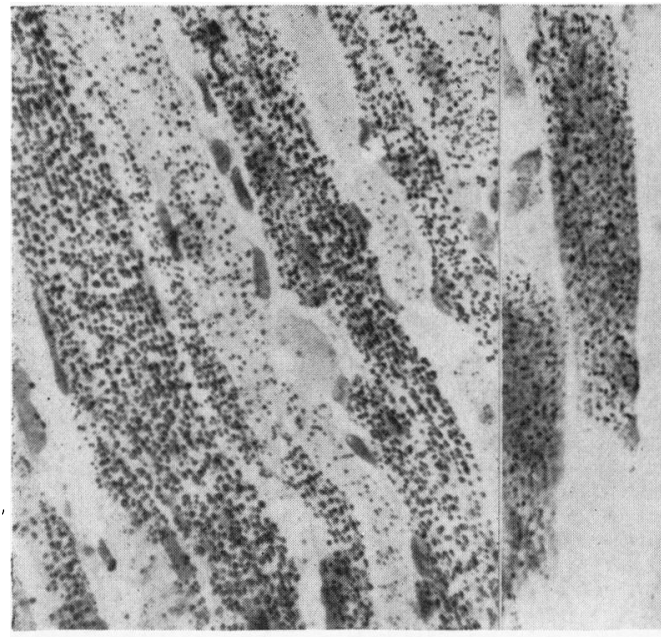

(a)

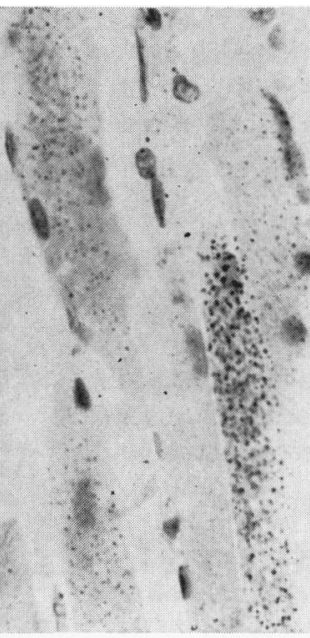

(b)

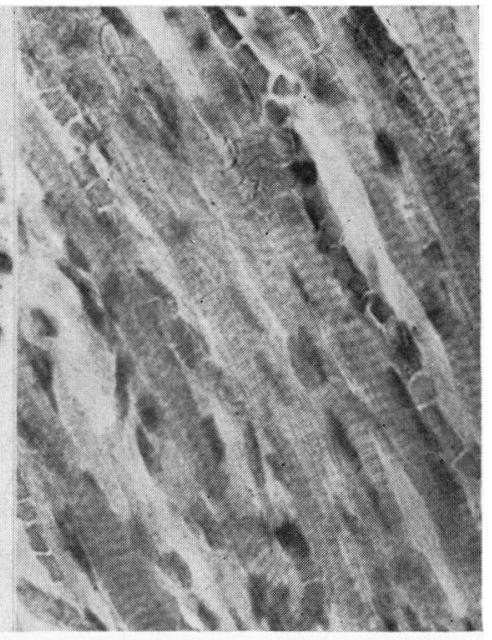

(c)

FIG. 3.-Diaphragm, showing (a) marked, (b) moderate, and (c) no fat infiltration. (Frozen section, Oil Red 0. $\times 300$.)

ence of fat droplets is commonly regarded as an index of disease.

The present study suggests that it may be otherwise in the neonatal period. Whether the infant was fed within the first two hours or starved; whether it contracted a Pseudomonas septicaemia or not; whether it lingered 48 hours in respiratory distress or died suddenly of intraperitoneal haemorrhage did not seem to influence the intensity of droplet infiltration. This appeared to depend only on postnatal age. It is true that many infants had suffered prenatal or postnatal hypoxia, or both. And even those who died suddenly passed necessarily through an agonal phase. It is conceivable therefore that a defect of oxidative metabolism may usually have been present. However, a similar infiltration of droplets may be seen in the tissues of healthy newborn rabbits killed by decapitation and fixed without delay (Aherne and Hull, unpublished, 1964).

The question therefore arises whether fat may be delivered to the cell at an unusual rate or in unusual amounts in the neonatal period. Rafstedt (1955) found that all serum lipids were low at birth in man but soon rose rather steeply. This was accompanied by a marked change in the ratio of $\alpha$ - to $\beta$-lipoprotein. In the first four days the total serum lipids increased $80-90 \%$; the increase in $\beta$-lipoprotein was more than $100 \%$. The rate of lipid increase was greater in mature than in premature infants. It appeared uninfluenced by diet. Van Duyne and Havel (1959), in a briefer study, found that the level of plasma unesterified fatty acid (UFA) was low at birth in both man and lamb but rose rapidly within the first two hours, and was still rising at $6 \frac{1}{2}$ hours after birth, when observations were discontinued. In one lamb experiment UFA had by then risen tenfold.

These observations may explain the correlation found in the present study between the degree of fat droplet infiltration and postnatal age. It seems reasonable to relate the number and size of droplets in parenchymal cells to the level of circulating lipid at the time of death. But in neither Rafstedt's study nor in that of Van Duyne and Havel did serum lipid rise unusually high. It is not clear, therefore, why droplet infiltration should be more striking than in older children. Moreover, Rafstedt observed a rise of serum lipid over several days, but in the present study fat droplet infiltration seemed at its most intense at 48 hours. It is possible that enzymes responsible for fat combustion have a low activity in the first day or so, and thereafter begin to cope with the increasing delivery of fat to the cell. But there is some evidence against this; it is established that the respiratory quotient falls to low levels in the early hours of life in man (Smith, 1945) and animal (Hard et al., 1944). Indeed, Hard et al. concluded from their studies on the guinea-pig that, after the exhaustion of liver glycogen in the first few hours after birth, energy is derived mainly from the metabolism of fat for several days. It is also possible that the severe carbohydrate depletion in most infants of this series (see Shelley, 1964) may have decelerated fat breakdown. But this cannot have been true of the healthy fed newborn rabbits, where a similar droplet infiltration has been seen.

The present study can only be descriptive. A 
simple explanation of the findings in terms of current morphological concepts does not emerge, and it is probable that experimental studies are needed. But it may be concluded that parenchymal fat droplet infiltration requires special interpretation when it is seen in the tissues of the newborn.

\section{Summary}

Fat droplet infiltration was studied in parenchymal and muscular tissues of 62 liveborn infants who died from various causes in the first few days of life, and 7 infants who were stillborn. In liveborn infants fat droplets progressively infiltrated parenchymal and muscular tissues in the first $\mathbf{4 8}$ hours, irrespective of clinical state or mode of death. The intensity of infiltration in this period was directly related to postnatal age. After 48 hours the relation with age seemed to disappear: the study was not pursued beyond 72 hours. In stillborn infants fat was demonstrable only in the bronchiolar mucosa. The findings may be partly interpreted as reflecting progressive fat mobilization in the early hours of life.

I am grateful to Dr. A. H. T. Robb-Smith, Dr. G. S. Dawes, and Dr. D. Hull for their advice, to Mr. Ian Burns for technical assistance, and to Dr. T. Parry for the photomicrographs.

\section{REFERENCES}

Dixon, K. C. (1958). Fatty deposition: a disorder of the cell. Quart. J. exp. Physiol., 43, 139.

Dorkin, J. R., and Weinberg, T. (1949). Normal occurrence of histologically demonstrable fat in the liver of the newborn infant. Arch. Path., 48, 578.

Emery, J. L., and Finch, E. (1954). The fat and water content of the left and right liver before and after birth. Arch. Dis. Childh., 29, 242.

Gruenwald, P. (1949). Degenerative changes in the right half of the liver resulting from intra-uterine anoxia. Amer. J. clin. Path., 19, 801 .

Hard, W. L., Reynolds, O. E., and Winbury, M. (1944). Carbohydrate, fat and moisture relationships in the pregnant, foetal and newborn guinea-pig. J. exp. Zool., 96, 189.

Rafstedt, S. (1955). Studies on serum lipids and lipoproteins in infancy and childhood. Acta paediat. (Uppsala), Suppl. 102, 44.

Scott, J. M. (1961). Fatty change in the myocardium of the newborn. Brit. med. J., 2, 1746.

Shelley, H. J. (1964). Carbohydrate reserves in the newborn infant. ibid., $1,273$.

Smallpeice, V., and Davies, P. A. (1964). Immediate feeding of premature infants with undiluted breast-milk. Lancet, 2, 1349.

Smith, C. A. (1945). The Physiology of the Newborn Infant. Thomas, Springfield, Illinois.

Tippett, L. H. C. (1952). The Methods of Statistics, 4th ed., p. 274. Williams and Norgate, London.

Van Duyne, C. M., and Havel, R. J. (1959). Plasma unesterified fatty acid concentration in fetal and neonatal life. Proc. Soc. exp. Biol. (N.Y.), 102, 599. 